\title{
Sistem pendukung keputusan prioritas anggaran belanja desa dengan Metode ANP-TOPSIS
}

\author{
Rianto*, A K Wardana \\ Program Studi Informatika, Fakultas Sain dan Teknologi, Universitas PGRI Yogyakarta \\ Email Korespondensi : *rian_r@ymail.com
}

\begin{abstract}
Abstrak. Anggaran belanja merupakan masalah yang sangat penting di dalam sebuah instansi, hal ini terkait dengan hasil yang akan diperoleh terhadap penggunaan anggaran tersebut. Selama ini perencanaan untuk pengalokasian anggaran belanja dibuat hanya berdasarkan faktor kebutuhan, tanpa ada mempertimbangan faktor-faktor penentu yang lain. Dengan permasalahan tersebut maka metode ANP-TOPSIS adalah solusi yang tepat untuk mengatasi masalah tersebut. Tujuan dari penelitian ini adalah membantu pengambil keputusan untuk menentukan prioritas anggaran belanja desa dengan memperhatikan faktor-faktor pendukung yang lain. Sehingga penggunaan dana tersebut dapat memberikan dampak yang jelas bagi masyarakat. Hasil dari peneltian ini diperoleh prioritas anggaran yaitu pada sektor sub bidang pemberdayaan perempuan, perlindungan anak dan keluarga dengan nilai skor 0,9420.
\end{abstract}

Kata Kunci : ANP-TOPSIS; Anggaran Belaja; sistem pendukung keputusan

\section{Pendahuluan}

Desa merupakan kesatuan masyarakat dimana tiap desa mempunyai batas wilayah dan mempunyai kewenangan untuk mengurus dan mengatur urusan pemerintahan demi kepentingan masyarakat di wilayah tersebut. Desa memiliki hak dan kewajiban terhadap aset yang menjadi milik desa, oleh karena itu dana desa yang menjadi pendapatan desa adalah hak desa, maka prioritas dalam penggunaan dana desa menjadi kewenangan desa. Dalam hal ini kewenangan otonomi desa harus didasari oleh desentralisasi dan lakukan dengan prinsip luas, nyata dan bertanggung jawab[1]. Untuk mengimbangi hal tersebut maka dalam pengelolaan dana desa terdapat badan permusyawaratan desa yang bertugas untuk merumuskan berbagai kebijakan dalam pembangunan desa dengan melalui musyawarah desa. Dalam hal ini prioritas anggaran desa harus dilakukan secara tepat agar desa mampu menyelenggarakan pembangunan desa dan terwujudnya peningkatan kualitas masyarakat desa dengan tolak ukur peningkatan kesejahteraan masyarakat.

Implementasi dalam pelaksanaan dana desa terdapat dua masalah utama yaitu pemberian dana desa yang semakin besar tiap tahunya tetapi jumlah dan kempuan sumber daya manusia (aparatur desa) tidak diimbangi, selain itu minimnya keterlibatan masyarakat untuk berpartisipasi dalam perencanaan penyusunan anggaran pendapatan dan belanja desa serta rencana nggaran pendapatan dan belanja desa, terlebih lagi untuk masalah pengawasan penggunaan dana desa[2], [3]. Kurangnya pengetahuan tentang 
penggunaan dana desa akan berdampak pada hasil dan rendahnya partisipasi masyarakat dalam penentuan program prioritas pembangunan serta pemberdayaan desa[4].

Prioritas pengalokasian anggaran dana desa menjadi masalah serius, hal ini dikarenakan belum adanya program prioritas untuk desa tersebut. Dari permasalahan tersebut maka dalam pengalokasian anggaran dana desa memperhatikan beberapa prinsip yaitu keadilan, kebutuhan prioritas, kewenangan desa, partisipatif, swakelola, tipologi desa. Dengan memperhatikan beberapa prinsip tersebut maka program prioritas anggaran tersebut disepakati dan diputuskan melalui musyawarah desa. Dari penelitian ini diperoleh bidang pembangunan desa dan pemberdayaan masyarakat menjadi prioritas utama dalam penggunaan anggaran dana desa. [5].

Pengalokasian anggaran pembangunan harus dapat mendorong dalam upaya pemberdayaan potensi daerah baik sumber daya alam dan manusia, dalam menentukan prioritas anggaran terdapat beberapa hal yang harus diperhatikan yaitu APBD tahun sekarang dikurangi oleh APBD tahun kemarin dan dibagi APBD tahun kemarin, dalam hal ini digunakan untuk menganalisa kesusuaian antar anggaran dan prioritas pembangunan yang dianalisis secara deskriptif [6].

Salah satu bagian penting dari pengelolaan keuangan daerah adalah perencanaan dan penganggaran, perencanaan pembangunan daerah harus memperhatikan beberapa faktor yaitu target yang jelas, konsistensi dan realistis, pengawasan yang berkelanjutan, pembiayaan, terukur, dan mempunyai batas waktu. Dari beberapa faktor tersebut akan diperoleh hasil penggunaan anggaran yang jelas untuk perencanaan pembangunan yang baik.[7]

Dari pemasalah tersebut maka pemilihan pritoritas anggaran belanja menjadi sangatlah penting. Dengan melihat dari penelitan-penelitian sebelumnya, dimana dalam menentukan prioritas anggaran harus memperhatikan beberapa faktor-faktor yang ada. Akan tetapi dalam penelitian sebelumnya tidak dijelaskan bagimana pemodelan dari faktor tersebut digunakan. Maka pada penelitian ini, selain memperhatikan faktor-faktor dalam menentukan prioritas anggaran, penggunaan metode ANP-TOPSIS juga digunakan dalam menentukan prioritas anggaran. Dengan hal ini, nilai kuantitatif dapat terlihat pada penelitian ini.

Tujuan dari penelitian ini adalalah membantu pengambil keputusan dalam menentukan prioritas anggaran belanja dana desa. Dengan metode ini penggunaan anggaran belanja dana desa akan lebih tepat sasaran dan dapat memberikan dapak kepada masyarakat secara jelas, khusunya untuk peningkatan kesejahteraan masyarat di desa tersebut.

\section{Metode Penelitian}

Penelitian ini dilakukan di wilayah Kabupaten Klaten, metode hibrid digunakan pada penelitian ini yaitu dengan menggabungkan metode ANP dan TOPSIS. ANP-TOPSIS adalah teknik pembobotan dan perangkingan untuk memecahkan permasalahan Multi Criteria Decision Making[8]. Metode ini telah banyak digunakan sebelumnya pendekatan dalam pengambilan keputusan[9], [10], [11], [12]. Fokus utama bidang pembuatan keputusan multi-kriteria untuk memperkenalkan prosedur[13]. ANP handal dalam pembobotan, akan tetapi untuk menambah kehandalan dari ANP, maka TOPSIS digunakan untuk menentukan peringkat alternatif[10]. Adapun alur penelitian yang digunakan dapat dilihat pada gambar 1. 


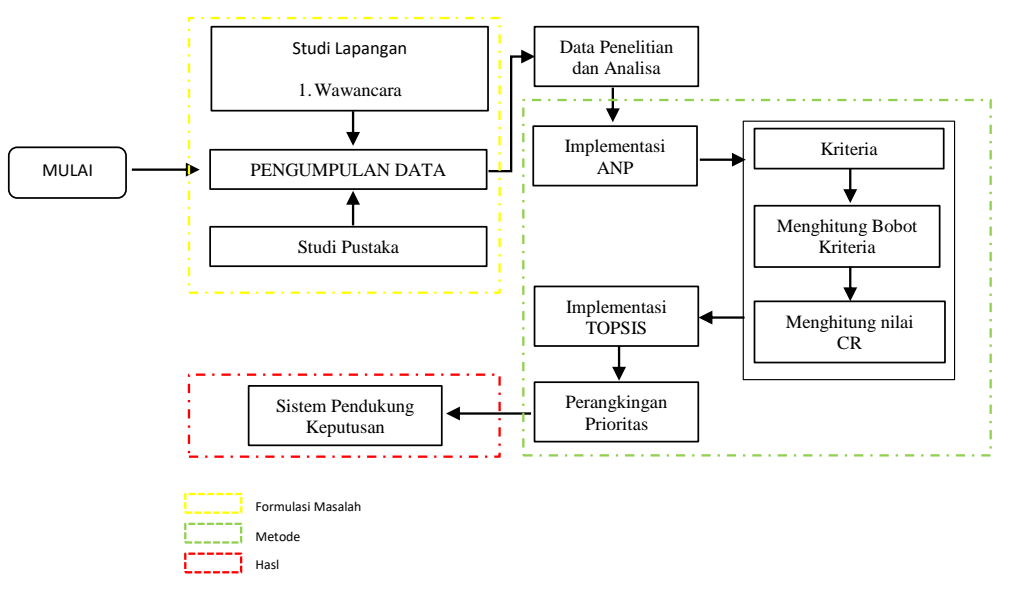

Gambar 1. Diagram alur penelitian

\subsection{Pengumpulan data}

Pada tahap ini pengumpulan data dibagi menjadi dua yaitu data primer dan data sekunder. Pada data primer data diambil dengan melakukan wawancara terhadap pihak-pihak yang terkait yaitu aparat pemerintah desa dan Badan Pemusyawaratan Desa untuk mendapatkan kriteria-kriteria yang akan digunakan. Kriteria-kriteria yang diperoleh pada tahap wawancara adalah biaya, waktu penyelesaian, dampak terhadap wilayah/ masyarakat, keuntungan investasi berkelanjutan, faktor kepentingan.

Selain wawancara pengambilan data secara langsung yaitu pengambilan data pada anggaran belanja dari dana desa yang telah berlangsung di kelurahan tersebut. Sedangkan pada data sekunder dengan mengambil literatur yang berasal dari jurnal, buku dan undang-undang tentang penggunaan dana desa dimana literatur-literatur tersebut mempunyai kaitan dengan anggaran belanja desa dan serta metode ANP dan TOPSIS. Melalui proses ini akan diperoleh kriteria, dimana kriteria tersebut akan digunakan pada metode ANP.

\subsection{ANP (Analytic Network Process)}

Metode ANP digunakan pada penelitian ini untuk mencari bobot masing-masing kriteria, dari nilai bobot yang telah diperoleh akan dilakukan pengujian untuk mendapatkan validasi dari hasil yang diperoleh. Nilai bobot yang dicari pada penelitan ini berupa kriteria biaya, kriteria waktu penyelesaian, kriteria dampak terhadap wilayah/ masyarakat, kriteria keuntungan investasi berkelanjutan, kriteria faktor kepentingan.

ANP dikembangkan untuk menghasilkan prioritas untuk sebuah keputusan tanpa membuat asumsi tentang hubungan hierarki searah antara tingkat keputusan [14], [15], dalam hal ini ANP mempunyai kemampuan yang lebih baik dibangdingkan dengan AHP, dimana ANP mampu menangani hubungan timbal balik antara tingkat keputusan dan atribut dengan memperoleh bobot komposit melalui pengembangan "supermatrix". Supermatrix adalah matriks dipartisi, di mana masing-masing submatrix terdiri dari serangkaian hubungan antara dua komponen atau cluster dalam struktur jaringan koneksi[16].

Untuk mendapatkan hasil akhir, langkah pertama adalah mengidentifikasi kriteria yang digunakan untuk menentukan priortas anggaran belanja. Langkah kedua adalah membangun hubungan saling ketergantungan antara kriteria untuk mendapatkan bobot kriteria mereka melalui pendekatan ANP. Selanjutnya, berdasarkan pada bobot yang saling tergantung dari sumber daya pemasaran, langkah keempat adalah membangun matriks pengambilan keputusan. Langkah terakhir adalah menerapkan metode TOPSIS untuk mendapatkan hasil akhir[17]. 
Pendekatan umpan balik dari struktur hiraki secara umum dapat digunakan untuk memperoleh prioritas yang saling ketergantungan[18]. Tahap dalam penggunaan metode ini adalah dengan membuat matrik perbandingan berpasangan sesuai dengan membandingkan nilai kepentingan tiap kriteria.

$$
\begin{array}{lll}
C_{11} & C_{12} & C_{13} \\
C_{21} & C_{22} & C_{23} \\
C_{31} & C_{32} & C_{33}
\end{array}
$$

Melakukan normalisasi matrik dengan membagi nilai dari tiap-tiap kriteria dari hasil penjumlahan tiap kolom.

$$
X_{i j}=\frac{C_{i j}}{\sum_{i=1}^{n} i j}
$$

Menghitung bobot masing-masing kriteria dengan menjumlahkan nilai baris tiap kriteria dibagi dengan jumlah kriteria.

$$
W_{i j}=\frac{\sum_{i-1}^{n} X_{i j}}{n}
$$

Implementasi dari metode ini yaitu pada tahap pembobotan tiap kriteria, akan tetapi harus dilakukan validasi terhadap nilai bobot tersebut dengan menguji nilai konsistensi rasio. Dimana untuk mencari nilai konsistensi rasio harus diperleh terlebih dahulu nilai eigen dan kemudian mencari nilai $\lambda$ max dengan menjumlahkan nilai eigen dari masing-masing baris kriteria.

$$
\lambda_{\max }=\sum_{i=1}^{n} C v_{i j}
$$

Pada tahap akhir untuk mengujian nilai konsistensi rasion yaitu dengan mencari nilai konsistensi indek terlebih dahulu, dari nilai tersebut akan dipereoleh nilai dari konsistensi rasio.

$$
\begin{gathered}
C I=\frac{\lambda_{\max }-n}{n-1} \\
C R=\frac{C I}{R C I}
\end{gathered}
$$

Pastikan pengujian nilai dari CR tidak akan lebih tinggi dari 0,10 atau $10 \%$ supaya nilai konsistensinya dapat diterima. Apabila nilai CR lebih dari 0,1 maka perhitungan harus dimulai dari awal.

\subsection{TOPSIS (Technique For Others References By Similarity To Ideal Solution)}

Metode TOPSIS adalah model pendekatan dengan pembobotan yang sederhana. Metode ini didasarkan pada konsep alternatif yang dipilih harus memiliki jarak terdekat dari solusi ideal dan terjauh dari solusi ideal negatif[19]. Metode TOPSIS adalah salah satu metode analisis keputusan multi-kriteria yang paling banyak digunakan[20], [21]. Pada penggunaan metode TOPIS, langkah pertama yaitu melakukan normalisasi matrik keputusan dimana nilai normalisasi $\left(\mathrm{r}_{\mathrm{ij}}\right)$ dihitung dengan menggunakan persamaan (7)

$$
r_{i j}=X_{i j} / \sqrt{\sum_{i=1}^{n} x_{i}^{2}, \forall i, j}
$$

Setelah normalisasi matrik diperoleh maka harus menghitung bobot normalisasi matrik keputusan, nilai bobot normalisasi vij dihitung dengan menggunakan persamaan (8).

$$
v_{i j}=w_{j} r_{i j . \forall i . j}
$$

Dimana $\mathrm{w}_{\mathrm{j}}$ adalah bobot dari kriteria ke-j dan $\sum_{j=1}^{m} w_{j}=1$

Mencari nilai dari solusi ideal positif dan solusi ideal negatif. Rumus solusi ideal positif dapat dilihat pada persamaan (9), sedangkan rumus dari solusi ideal negatif dapat dilihat pada persamaan (10).

$$
\begin{aligned}
& A^{+}=\left\{v_{1}^{*}, \ldots, v_{m}^{*}\right\}=\left\{\left(\max _{i} v_{i j} \mid j \in C_{b}\right),\left(\min _{i} v_{i j} \mid j \in C_{c}\right)\right\} \\
& A^{-}=\left\{v_{1}^{-}, \ldots, v_{m}^{-}\right\}=\left\{\left(\min _{i} v_{i j} \mid j \in C_{b}\right),\left(\max _{i} v_{i j} \mid j \in C_{c}\right)\right\}
\end{aligned}
$$


Dari persamaan (5) dan (6) terdapat nilai $\mathrm{Cb}$ dan nilai $\mathrm{C}_{\mathrm{c}}$, nilai $\mathrm{C}_{\mathrm{b}}$ adalah atribut dari kriteria keuntungan dan $\mathrm{C}_{\mathrm{c}}$ atribut dari kriteria biaya.

Mencari nilai jarak setiap alternatif antara nilai dari solusi ideal positif dan solusi ideal negatif, jarak alternatif dari solusi ideal negatif adalah sebagai berikut:

$$
S_{i}^{+}=\sqrt{\sum_{j=1}^{m}\left(v_{i j}-v_{j}^{+}\right)^{2}}, \forall i
$$

Sedangkan jarak alternatif dari solusi ideal positif adalah sebagai berikut:

$$
S_{i}^{-}=\sqrt{\sum_{j=1}^{m}\left(v_{i j}-v_{j}^{-}\right)^{2}}, \forall i
$$

Menghitung nilai dari preferensi setiap alternatif, untuk menghitung nilai preferensi dapat menggunakan persamaan (9).

$$
R C_{i}^{*}=\frac{S_{i}^{-}}{S_{i}^{+}+S_{i}^{-}}, \forall i
$$

Nilai RC yang paling besar menunjukkan bahwa alternatif tersebut yang akan dipilih.

\section{Hasil dan Pembahasan}

Pada penelitian ini menggunakan lima kriteria yang diperoleh dari hasil wawancara yaitu (A) biaya; (B) waktu penyelesaian; (C) dampak terhadap wilayah/masyarakat; (D) keuntungan investasi berkelanjutan; (E) faktor kepentingan. Penggunaan metode ANP pada tahap ini untuk mencari nilai bobot dari masingmasing kriteria. Setelah hasil pembobotan diperoleh, maka nilai tersebut harus dilakukan pengujian dengan mencari nilai CI dimana nilai CI harus lebih kecil dari 10\% atau 0,1. Apabila pada tapah validasi terhadap pengujian nilai CI dapat dipertanggung-jawabkan, maka dapat masuk pada tahap berikutnya yaitu implementasi dari metode TOPSIS. TOPSIS digunakan untuk mencari perangkingan terhadap alternatif-alternatif yang akan dipilih..

\subsection{Pembobotan nilai kriteria}

Tahap pertama yang dilakukan untuk mencari bobot masing-masing kriteria yaitu membuat matrik perbandingan berpasangan, dimana pemberian nilai diberikan berdasarkan nilai kepentingan dari kriteria dengan membandingkan nilai kepentingan terhadap kriteria dengan kriteria yang lain dengan menggunakan persamaan (1). Setelah matrik perbandingan berpasangan diperoleh maka harus dilakukan normalisasi matriks dengan menggunakan persamaan (2), dimana hasil dari normalisasi matrik dapat dilihat pada Tabel I.

Tabel 1. Normalisai matrik

\begin{tabular}{cccccc}
\hline Kriteria & A & B & C & D & E \\
\hline A & 0,2500 & 0,3158 & 0,2000 & 0,2143 & 0,3896 \\
B & 0,0833 & 0,1053 & 0,1333 & 0,1429 & 0,0649 \\
C & 0,5000 & 0,3158 & 0,4000 & 0,2143 & 0,3896 \\
D & 0,0833 & 0,0526 & 0,1333 & 0,0714 & 0,0260 \\
E & 0,0833 & 0,2105 & 0,1333 & 0,3571 & 0,1299 \\
\hline
\end{tabular}

Setelah nilai dari normalisasi matrik diperoleh, maka tahap berikutnya adalah menghitung nilai bobot dari masing-masing kriteria, untuk mencari bobot masing-masing kriteria menggunakan persamaan (3). Hasil nilai bobot masing-masing kriteria dapat dilihat pada tabel 2. 
Tabel 2. Nilai bobot masing-masing kriteria

\begin{tabular}{lc}
\hline \multicolumn{1}{c}{ Kriteria } & Bobot \\
\hline Biaya & 0,2739 \\
Waktu penyelesaian & 0,1059 \\
Dampak terhadap wilayah/masyarakat & 0,3639 \\
Keuntungan investasi berkelanjutan & 0,0733 \\
Faktor kepentingan & 0,1828 \\
\hline
\end{tabular}

Hasil dari pembobotan terhadap masing-masing kriteria, diperoleh bobot kriteria paling besar yaitu kriteria $C$ yaitu dampak terhadap wilayah/masyarakat dengan nilai 0,3639 sedangkan nilai bobot kriteria paling kecil yaitu kriteria $D$ yaitu keuntungan investasi berkelanjutan dengan bobot 0,0733 . Setelah nilai bobot diperoleh, maka untuk menguji nilai konsistensinya maka harus dicari nilai CR. Untuk mencari nilai CR dapat menggunakan persamaan (6), akan tetapi sebelum mencari nilai CR, maka nilai CI harus diperoleh terlebih dahulu. Sedangkan untuk mencari nilai CI dapat menggunakan persamaan (5). Berdasahkan hasil yang diperoleh pada tabel 2 maka dilakukan pengujian nilai CR. Dari hasil pengujian tersebut diperoleh nilai CR adalah 0,0901, jadi nilai CR <0,1 maka nilai konsistensi dapat diterima. Pada tahap ini pengimplentasian metode ANP telah selesai, sedangkan perangkingan menggunakan metode TOPSIS.

\subsection{Alternatif pilihan}

Penilaian dari alternatif-alternatif yang diperoleh dilakukan dengan teknik wawancara dimana untuk skala penilaian diambil dengan rentang nilai 1 - 5 untuk kriteria dampak, keuntungan investasi berkelanjutan dan faktor kepentingan. Pada tabel 3 adalah alternatif pilihan yang digunakan, dari alternatif-alternatif tersebut harus dilakukan prioritas anggaran yang harus dijalankan terlebih dahulu.

Tabel 3. Alternatif-alternatif pilihan (alokasi anggaran belanja dana desa tahun 2019

\begin{tabular}{ll}
\hline & \multicolumn{1}{c}{ Alternatif Pilihan } \\
\hline K1 & Sub Bidang Pendidikan \\
K2 & Sub Bidang Kesehatan \\
K3 & Sub Bidang Pekerjaan Umum dan Penataan Ruang \\
K4 & Sub Bidang Kawasan Pemukiman \\
K5 & Sub Bidang Perhubungan, Komunikasi dan Informatika \\
K6 & Sub Bidang Pariwisata \\
K7 & Sub Bidang Ketentraman, Ketertiban Umum dan Perlindungan Masyarakat \\
K8 & Sub Kebudayaan dan Keagamaan \\
K9 & Sub Bidang Kepemudaan dan Olahraga \\
K10 & Sub Bidang Kelembagaan Masyarakat \\
K11 & Sub Kelautan dan Perikanan \\
K12 & Sub Bidang Pertanian dan Peternakan \\
K13 & Sub Bidang Peningkatan Kapasitas Aparatur Desa \\
K14 & Sub Bidang Pemberdayaan Perempuan, Perlindungan Anak dan Keluarga \\
K15 & Sub Bidang Dukungan Penanaman Modal \\
\hline
\end{tabular}


Tabel 4. Normalisai matrik

\begin{tabular}{cccccc}
\hline Alternatif & \multicolumn{5}{c}{ Normalisasi Matrik } \\
\hline K1 & 0,0340 & 0,2357 & 0,3418 & 0,2566 & 0,2655 \\
K2 & 0,0489 & 0,2062 & 0,3418 & 0,2566 & 0,3319 \\
K3 & 0,9689 & 0,1179 & 0,3418 & 0,1925 & 0,1991 \\
K4 & 0,2246 & 0,2062 & 0,2051 & 0,1925 & 0,1991 \\
K5 & 0,0128 & 0,1473 & 0,1367 & 0,1925 & 0,2655 \\
K6 & 0,0440 & 0,3241 & 0,2051 & 0,3208 & 0,1991 \\
K7 & 0,0293 & 0,3536 & 0,2734 & 0,2566 & 0,1991 \\
K8 & 0,0323 & 0,3536 & 0,3418 & 0,2566 & 0,1991 \\
K9 & 0,0073 & 0,3536 & 0,2051 & 0,1925 & 0,1991 \\
K10 & 0,0293 & 0,3536 & 0,2051 & 0,1925 & 0,1991 \\
K11 & 0,0381 & 0,2652 & 0,1367 & 0,3208 & 0,2655 \\
K12 & 0,0037 & 0,2062 & 0,2734 & 0,3208 & 0,3319 \\
K13 & 0,0026 & 0,0884 & 0,1367 & 0,1925 & 0,2655 \\
K14 & 0,0241 & 0,2357 & 0,3418 & 0,3208 & 0,3319 \\
K15 & 0,0147 & 0,2062 & 0,2051 & 0,3208 & 0,3319 \\
\hline
\end{tabular}

Setelah Penilian dari semua alternatif telah diperoleh maka tahap berikutnya adalah melakukan normalisasi matrik. Normalisasi matrik dapat menggunakan persamaan (7), dimana hasil dari normalisasi matrik dapat dilihat pada tabel 4.

Setelah nilai dari normalisasi matrik selesai, maka tahap berikutnya adalah mengitung nilai bobot normalisasi matrik keputusan dengan menggunakan persamaan (8). Hasil dari bobot normalisasi matrik dapat dilihat pada tabel 5.

Tabel 5. Bobot normalisa matrik keputusan

\begin{tabular}{lllll}
\hline 0,0093 & 0,0250 & 0,1244 & 0,0188 & 0,0485 \\
0,0134 & 0,0218 & 0,1244 & 0,0188 & 0,0607 \\
0,2654 & 0,0125 & 0,1244 & 0,0141 & 0,0364 \\
0,0615 & 0,0218 & 0,0746 & 0,0141 & 0,0364 \\
0,0035 & 0,0156 & 0,0498 & 0,0141 & 0,0485 \\
0,0120 & 0,0343 & 0,0746 & 0,0235 & 0,0364 \\
0,0080 & 0,0375 & 0,0995 & 0,0188 & 0,0364 \\
0,0088 & 0,0375 & 0,1244 & 0,0188 & 0,0364 \\
0,0020 & 0,0375 & 0,0746 & 0,0141 & 0,0364 \\
0,0080 & 0,0375 & 0,0746 & 0,0141 & 0,0364 \\
0,0104 & 0,0281 & 0,0498 & 0,0235 & 0,0485 \\
0,0010 & 0,0218 & 0,0995 & 0,0235 & 0,0607 \\
0,0007 & 0,0094 & 0,0498 & 0,0141 & 0,0485 \\
0,0066 & 0,0250 & 0,1244 & 0,0235 & 0,0607 \\
0,0040 & 0,0218 & 0,0746 & 0,0235 & 0,0607 \\
\hline
\end{tabular}

Setelah nilai bobot normalisasi matrik kepetusuan diperoleh, maka tahap berikutnya adalah mencari nilai solusi ideal positif dan nilai solusi ideal negatif. Untuk mencari nilai solusi ideal positif dengan 
menggunakan persamaan (9) dan nilai solusi ideal negatif dapat menggunakan persamaan (10). Hasil nilai dari solusi ideal positif dan negatif dapat dilihat pada tabel 6 .

Tabel 6. Nilai solusi ideal positif dan nilai solusi ideal negatif

\begin{tabular}{cccc}
\hline Kriteria & Bobot & $\mathrm{A}^{+}$ & $\mathrm{A}^{-}$ \\
\hline A & 0,2739 & 0,000702 & 0,265425 \\
B & 0,1059 & 0,009364 & 0,037457 \\
C & 0,3639 & 0,124391 & 0,049756 \\
D & 0,0733 & 0,023524 & 0,014114 \\
E & 0,1828 & 0,060678 & 0,036407 \\
\hline
\end{tabular}

Nilai solusi ideal positif dan nilai solusi ideal negatif telah diperoleh, maka tahap berikutnya adalah mencari nilai jarak alternatif solusi ideal positf dengan menggunakan persamaan (11) dan nilai jarak alternasif ideal negatif dengan menggunakan persaan (12). Setelah kedua nilai tersebut diperoleh maka tahap yang terakhir adalah mencari nilai prefesensi setiap alternatif menggunakan persamaan (13). Hasil dari perhitungan tersebut dapat dilihat pada tabel 7.

Tabel 7. Hasil perangkingan prioritas anggaran

\begin{tabular}{ccccc}
\hline Alternatif & D+ & D- & RC & Prioritas \\
\hline K1 & 0,0221 & 0,2674 & 0,9238 & 3 \\
K2 & 0,0184 & 0,2645 & 0,9349 & 2 \\
K3 & 0,2660 & 0,0787 & 0,2283 & 15 \\
K4 & 0,0837 & 0,2060 & 0,7110 & 14 \\
K5 & 0,0765 & 0,2631 & 0,7747 & 12 \\
K6 & 0,0618 & 0,2548 & 0,8048 & 9 \\
K7 & 0,0455 & 0,2622 & 0,8521 & 6 \\
K8 & 0,0383 & 0,2673 & 0,8747 & 5 \\
K9 & 0,0628 & 0,2646 & 0,8082 & 8 \\
K10 & 0,0632 & 0,2586 & 0,8036 & 10 \\
K11 & 0,0785 & 0,2556 & 0,7650 & 13 \\
K12 & 0,0278 & 0,2708 & 0,9068 & 4 \\
K13 & 0,0762 & 0,2665 & 0,7776 & 11 \\
K14 & 0,0167 & 0,2709 & 0,9420 & 1 \\
K15 & 0,0514 & 0,2643 & 0,8372 & 7 \\
\hline
\end{tabular}

Pada tabel 7 adalah perangkingan prioritas anggaran belanja dana desa. Dari hasil tersebut diperoleh bahwa alternatif K14 adalah prioritas utama dari beberapa alteratif yang lain.

Tabel 8. Perbandingan prioritas anggaran yang telah berjalan dengan penelitian yang telah dilakukan

\begin{tabular}{ccc}
\hline Alternatif & Prioritas Telah Berjalan & Penelitian \\
\hline K1 & 3 & 3 \\
K2 & 2 & 2 \\
K3 & 15 & 15 \\
K4 & 11 & 14 \\
K5 & 12 & 12 \\
K6 & 6 & 9
\end{tabular}




\begin{tabular}{ccc} 
K7 & 5 & 6 \\
K8 & 9 & 5 \\
K9 & 8 & 8 \\
K10 & 10 & 10 \\
K11 & 13 & 13 \\
K12 & 4 & 4 \\
K13 & 14 & 11 \\
K14 & 1 & 1 \\
K15 & 7 & 7 \\
\hline
\end{tabular}

Pada tabel 8 adalah perbandingan dari prioritas anggaran yang telah dilaksanakan oleh kelurahan Jaden tahun anggaran 2019 dengan prioritas anggaran yang diusulkan dalam penelitian dengan menggunakan metode ANP-TOPSIS. Berdasarkan perbandingan prioritas anggaran belanja tersebut mempunyai tingkat kesamaan sebesar 73,33\%, sehingga metode ini sangat cocok digunakan sebagai alat bantu pengambilan keputusan untuk prioritas anggaran belanja dana desa.

\section{Kesimpulan}

ANP-TOPSIS merupakan salah satu metode hibrid yang dapat digunakan dalam pengambilan keputusan. Metode ini dapat digunakan untuk mengurangi kelemahan manusia dalam pengambilan keputusan dengan hasil yang lebih akurat. Pada penelitian ini ANP-TOPSIS digunakan sebagai alat bantu dalam pengambilan keputusan untuk melakukan perangkingan prioritas alokasi anggaran belanja desa di wilayah Klaten. Berdasarkan hasil tersebut maka prioritas utama alokasi anggaran belanja desa adalah sub bidang pemberdayaan perempuan, perlindungan anak dan keluarga dan prioritas yang paling akhir adalah sub bidang pekerjaan umum dan penataan ruang.

\section{Ucapan Terima Kasih}

Terima kasih kami ucapkan kepada Lembaga Penelitan dan Pengabdian Masyarakat Universitas PGRI Yogyakarta yang telah mendanai penelitian ini sehingga penelitian ini dapat terlaksana dan berjalan dengan lancar..

\section{Daftar Pustaka}

[1] H. Sabarno, Memandu Otonomi Daerah Menjaga Kesatuan Bangsa. Jakarta: Sinar Grafika, 2007.

[2] N. L. L. Aziz, "Otonomi Desa dan Efektivitas Dana Desa," J. PenelitianPolitik, vol. 13, no. 2, pp. 193-211, 2017.

[3] Y. Maulana, "Membangun Kemandirian Desa dalam Bingkai Otonomi Daerah," J. Penelit. Polit., vol. 13, no. 2, pp. 261-268, 2016.

[4] K. D. Apriani, "Respon Publik terhadap Model Penganggaran Partisipatif dalam Pembangunan Desa: Studi Tiga Provinsi di Indonesia," J. Penelit. Polit., vol. 13, no. 2, pp. 137-148, 2016.

[5] D. A. Noviyanti; Gamaputra, Gading; Lestari, Yuni; Utami, "Pengidentifikasian Pendapatan dan Prioritas Pembangunan Dana Desa," J. Ilmu Adm. Publik, vol. 3, no. 2007, pp. 112-121, 2018.

[6] P. A. Wardhani, "Analisa Alokasi Anggaran dan Prioritas Pembangunan Daerah di Kabupaten Sarolangun," Efikasi Diri dan Pemahaman Konsep IPA dengan Has. Belajar Ilmu Pengetah. Alam Siswa Sekol. Dasar Negeri Kota Bengkulu, vol. 6, pp. 149-156, 2015.

[7] D. I. Barbakem, J. J. Tinangon, and H. Sabijono, "Analisis Perencanaan Dan Penganggaran Untuk Anggaran Pendapatan Dan Belanja Daerah Pada Badan Keuangan Kabupaten Kepulauan Sangihe Tahun Anggaran 2015," Going Concern J. Ris. Akunt., vol. 13, no. 1, pp. 1-13, 2018.

[8] H. Zhang, J. Wang, and X. Chen, "An outranking approach for multi-criteria decision-making problems with interval-valued neutrosophic sets," Neural Comput. Appl., vol. 27, no. 3, pp. 615$627,2016$.

[9] S. Kar and K. N. Jha, "Assessing criticality of construction materials for prioritizing their procurement using ANP-TOPSIS," Int. J. Constr. Manag., vol. 0, no. 0, pp. 1-11, 2020. 
[10] M. Abdel-Basset, M. Mohamed, and F. Smarandache, "A hybrid neutrosophic group ANPTOPSIS framework for supplier selection problems," Symmetry (Basel)., vol. 10, no. 6, pp. 1-22, 2018.

[11] A. A. . P. Ardyanti, N. Purnama, and N. L. Nyajentari, "Sistem Pendukung Keputusan Siswa Berprestasi SMA Dwijendra Denpasar dengan Metode ANP \& Topsis," J. Inf., vol. 2, no. 2, 2017.

[12] R. Gustriansyah, "Sistem Pendukung Keputusan Pemilihan Dosen Berprestasi Dengan Metode Anp Dan Topsis," Semin. Nas. Teknol. Inf. dan Komun., vol. 2016, no. Sentika, p. 8, 2016.

[13] R. F. de F. Aires and L. Ferreira, "A new approach to avoid rank reversal cases in the TOPSIS method," Comput. Ind. Eng., vol. 132, no. August 2018, pp. 84-97, 2019.

[14] E. Rokou, "International Symposium on Analytic Hierarchy Process - ISAHP 2018," Int. J. Anal. Hierarchy Process, vol. 9, 2017.

[15] K. Shahroudi and H. Rouydel, "Using a multi-criteria decision making approach (ANP-TOPSIS) to evaluate suppliers in Iran's auto industry," Int. J. Appl. Oper. Res. J., vol. 2, no. 2, pp. 37-48, 2012.

[16] O. Bayazit, "Use of analytic network process in vendor selection decisions," Benchmarking, vol. 13, no. 5, pp. 566-579, 2006.

[17] C. S. Wu, C. T. Lin, and C. Lee, "Optimal marketing strategy: A decision-making with ANP and TOPSIS," Int. J. Prod. Econ., vol. 127, no. 1, pp. 190-196, 2010.

[18] T. L. Saaty, "Fundamentals of the Analytic Hierarchy Process," pp. 15-35, 2001.

[19] E. K. Zavadskas, J. Antucheviciene, T. Vilutiene, and H. Adeli, "Sustainable decision-making in civil engineering, construction and building technology," Sustain., vol. 10, no. 1, 2017.

[20] L. Ferreira, D. Borenstein, M. B. Righi, and A. T. de Almeida Filho, "A fuzzy hybrid integrated framework for portfolio optimization in private banking," Expert Syst. Appl., vol. 92, pp. 350-362, 2018.

[21] M. Behzadian, S. Khanmohammadi Otaghsara, M. Yazdani, and J. Ignatius, "A state-of the-art survey of TOPSIS applications,” Expert Syst. Appl., vol. 39, no. 17, pp. 13051-13069, 2012. 